\title{
Question classification taxonomies as guides to formulating questions for use in chemistry classrooms
}

\author{
Kayima Festo \\ Department of Chemistry, University of Bergen, Bergen, Norway \\ For correspondence: kayimawkn@gmail.com, festo.kayima@uib.no
}

\begin{abstract}
Teacher questions play an important role in facilitating classroom discourse. Using appropriate question types and proper questioning techniques help to create reflective- active learners. Teacher questions can elicit students' explanations, elaboration of their ideas and thinking, and they can be used to disclose students' misconceptions. Despite knowing about the benefits of good questioning, most classroom teachers fail to question their students in ways which go beyond mere requests for explicit, factual information. Several of the question taxonomies developed in the past for classifying teachers' questions exhibit a potential to serve as guiding frameworks for teachers in formulating and using questions. This paper examines the extent to which existing question classification taxonomies could guide chemistry teachers in developing and using classroom questions. A framework is also suggested to guide chemistry teachers in formulating and using the desired kinds of questions.
\end{abstract}

Keywords: teacher questions, question classification, question formulation, taxonomy of questions

\section{Introduction}

Teacher classroom questions are important tools for facilitating students' understanding of chemical language and concepts. Appropriate use of questions mediates students' knowledge construction and influence the type of cognitive processes engaged in (Alison, 1994; Roth, 1996). Teacher questions can also facilitate students' acquiring of specific languages unique to individual subjects (Mortimer \& Scott, 2003), vocabulary and representational practices of a subject. Regardless of their potential contribution to learning, developing and using good questions is challenging to most classroom teachers (Graesser \& Person, 1994). Most often, a large part (60 \%) of teacher questions only request explicit, factual information from students (Gall, 1970; Hannel, 2009; Lee \& Kinzie, 2012).

There are several question classification taxonomies developed in the past with a perceived potential to guide teachers in formulating and using classroom questions. These have been identified and summarized by researchers Crump (1970); Gall (1970); Riegle (1976) and Wilen (1986). In the past, there have been also efforts by researchers to train classroom teachers in questioning techniques and in using some of the existing question classification taxonomies. Classroom teachers were reported to change in their practice of questioning after undergoing training in the use of specific question classification taxonomies (Galassi, Gall, Dunning, \& Banks, 1974; Gilbert, 1992; Godbold, 1973; Hamblen, 1984; Wilen, 1991). However, it was also noticed that those teachers who had been trained in several questioning techniques often failed to implement those skills in a pervasive and continuous way (N. M. Sanders, 1972). This is thought to be attributed to the existing gap between how teachers and researchers view the role of questions (Eshach, Dor-Ziderman, \& Yefroimsky, 2014), the unsuitability of a number of question taxonomies to classroom settings (Furst, 1981), teachers' beliefs about teaching and learning which seem inconsistent with using question taxonomies, the complexity of the taxonomies themselves (Anderson, 1994), and the inconsistencies in meanings and terms used in several question classification taxonomies which end up confusing teachers (Reed, 1977). 
Despite the concerns reported about the teachers' inability to continuously apply the learned questioning techniques, education researchers contend that question classification taxonomies can help teachers to match the questions they ask with the type of thinking that they are trying to develop (Hannel, 2009; Vogler, 2005; Wimer, Ridenour, Thomas, \& Place, 2001). The taxonomies are also perceived to support teachers in formulating questions and clarifying instructional objectives (Allen \& Tanner, 2002; Kastberg, 2003).In this article, analysis is made of the existing question classification taxonomies to assess their potential as frameworks that could guide teachers in formulating and using questions in chemistry classrooms.

\section{Question classification taxonomies}

Originally question classification systems were understood as systematic observation instruments that could be used in the observation and collection of objective data on such aspects of questions as cognitive level, length and frequency (Wilen, 1991). This kind of explanation draws from that much interest during 1950s and 1960s, when researchers needed to study, identify and analyze classroom thinking operations, instructional goals and teaching activities (Clegg, 1987; Wilen, 1991). However, researchers did not only stop at studying and characterizing teachers' classroom practices, but they also wanted to improve the way teachers executed their practices. As such, several researchers focused on developing question taxonomies to guide and impact on classroom teacher questioning behaviors. Thus, several sets of categories into which teachers' questions can or could be classified were developed by several researchers (Crump, 1970; Gall, 1970; Riegle, 1976; Wilen, 1986).

Bloom, Engelhart, Furst, Hill, and Krathwohl (1956) developed a classification scheme of educational objectives in the cognitive domain where six hierarchical classes of objectives (simple to complex intellectual operations) were identified. These intellectual operations included; knowledge, comprehension, application, analysis, synthesis and evaluation. Around the same period, Guilford (1956) devised a three-dimensional model of intellectual processes, classifying mental abilities. The feature in Guilford's model that provoked the most interest related to classroom questioning was the identification of convergent and divergent thinking processes as they relate to creativity (Clegg, 1987, p. 15). Gallagher and Aschner (1963) using Guilford's work, constructed a category system to examine teacher-student classroom interaction. Their system comprised of five question types often found in teaching situations (cognitive memory, convergent, divergent, evaluative and routine questions). A number of question classification taxonomies that emerged later were built based on either the work of Bloom et al. (1956) and or Gallagher and Aschner (1963)'s conceptualization of questions.

Generally, up to 41 different authors have made suggestions of different question categories which altogether reflect the conceptualizations of Bloom et al. (1956) and or Gallagher and Aschner (1963). This list includes; Adams (1964); Anderson et al. (2001); Aschner (1961); Barnes (1969); Biber, Johansson, Leech, Conrad, and Finegan (1999); Bloom et al. (1956); Blosser (1973); Carner (1963); Chinn, Anderson, and Waggoner (2001); Christenbury and Kelly (1983); M. H. Clements, Fielder, and Tabachnick (1966); R. D. Clements (1964); Crump (1970); Davis and Tinsley (1967); Douglass (1967); Elstgeest (1985); Enokson (1973); Fraenkel (1966); Gallagher and Aschner (1963); Galton, Simon, and Croll (1980); Graesser, Person, and Huber (1992); Guszak (1967); Herber (1978); Hunkins (1972); Hyman (1979); Kaiser (1979); Long and Sato (1983); Marzano (2001); Minor (1966); Moyer (1965); Nystrand and Gamoran (1997); Parsons (1968); Pate and Bremer (1967); Riegle (1976); Ruddell (1974); N. M. Sanders (1966); Schreiber (1967); B. O. Smith, Meux, and Coombs (1960); R. J. Smith (1969); Taba (1967), and (Wilen, 1985).

Given that the existing question classification taxonomies or question category systems were all developed based on the conceptualizations of two independent authors as we have mentioned in the previous two paragraphs, it is reasonable to say that there are majorly two ways of classifying questions despite having several versions of classification systems by different researchers. The first way of classifying questions is the non-hierarchical form where questions are classified as convergent or divergent originally from Gallagher and Aschner (1963). Other non-hierarchical forms of classifying questions involve using terms such as open and closed (Blosser, 1973), real and synthetic (Minor, 1966), authentic and test questions (Nystrand \& Gamoran, 1997). The second way of 
classifying questions is to classify them based on their cognitive level or complexity (Bloom et al., 1956).

In this paper I analyze five different question taxonomies suggested by different researchers, N. M. Sanders (1966), Fraenkel (1966), Minor (1966), Blosser (1973), and Nystrand and Gamoran (1997), examining the extent to which they could serve as question formulating guides to chemistry teachers. N. M. Sanders (1966)'s taxonomy is an adaptation of Bloom's cognitive categories and its selection represents all other question taxonomies which classify questions based on the complexity of cognitive levels. Fraenkel (1966) devised a taxonomy of questions based on the purpose the question is to address and his taxonomy was selected for analysis because of this feature which is not common to most other taxonomies. Minor (1966) and Nystrand and Gamoran (1997)'s question categories were selected because the authors use unique terms ('real/synthetic' and 'authentic/test' respectively) to characterize questions, which terms are not common to other question taxonomies. Blosser (1973)'s question category system was selected for those category systems which distinguish questions into closed and open categories. Table 1 shows a summary of question categories of the selected taxonomies by different authors.

Table 1: A summary of question categories by selected authors

\begin{tabular}{|c|c|c|c|c|}
\hline Authors & \multicolumn{4}{|c|}{ Question categories } \\
\hline N. M. Sanders (1966) & \multicolumn{4}{|c|}{$\begin{array}{l}\text { (i) Memory, (ii) Translation, (iii) Interpretation, (iv) Application, (v) Analysis, (vi) Synthesis, (vii) } \\
\text { Evaluation }\end{array}$} \\
\hline \multirow[t]{5}{*}{ Fraenkel (1966) } & Purpose & Type of question & Student action desired & \\
\hline & Knowledge acquisition & Factual & Remembering & \\
\hline & Knowledge synthesis & Descriptive & Remembering & \\
\hline & Knowledge synthesis & Explanatory & Reasoning/exercising judgement & \\
\hline & Creative thought & Heuristic & Divergent thinking & \\
\hline Minor (1966) & \multicolumn{4}{|c|}{ (i) Real questions and (ii) Synthetic questions } \\
\hline Blosser (1973) & \multicolumn{4}{|c|}{ (i) Managerial questions, (ii) Rhetorical questions, (iii) Closed and (iv) open questions } \\
\hline $\begin{array}{ll}\text { Nystrand } & \text { and } \\
\text { Gamoran (1997) }\end{array}$ & \multicolumn{4}{|c|}{ (i) Authentic questions and (ii) Test questions } \\
\hline
\end{tabular}

Analyzing question taxonomies for their possible use in chemistry classrooms

Analysis as used here implies breaking the topic, concept, and themes or terms down into parts in order to inspect, understand and or restructure them in a way that makes sense with respect to an individual interpretation of meaning and perception. The process involves reading the author's contribution and identifying its strengths and weakness with respect to the purpose and intentions of the analysis. In analyzing the question taxonomies, emphasis was on figuring out what the individual authors implied (meaning of the used terms, explanations, illustrations or interventions). Based on the respective authors' arguments, comments and conclusions were made to the content (text, terms, frameworks, or interventions), with respect to the usefulness and applicability of the respective taxonomies as question formulation-guiding frameworks to chemistry teachers. Overall, the analysis involved two important steps;

i. $\quad$ Reading the article as whole, determining the purpose, structure and the direction of the paper:

The individual articles were read as a whole in order to establish authors' statements of purpose, the respective authors' main points and the target audience, accounts of evidence that the authors used and any identified limitations or gaps.

i. Critiquing, assessing and evaluating the article's content/themes/terms or taxonomies with respect to the aim of the analysis.

A personal reaction to the works of the article was made. This part involved thinking about the respective authors' nature of conceptualizing questions, the proposals made, the terms or question 
labels used and the meanings the authors attached to the different terms used in the question taxonomies. This was followed by trying to envision how the proposed schemes could be used in the teaching situation, also given from the analyst's personal experience as a teacher, and from empirical accounts about teacher beliefs and perceptions about questioning.

\section{N. M. Sanders (1966)'s taxonomy of questions}

Sanders adopted Bloom et al. (1956)'s taxonomy of educational objectives to devise a taxonomy of questions, seeking to demonstrate the potential of applying Bloom's taxonomy to everyday classroom situations. Sanders used Bloom's model as a guide for identifying and describing the many types of questions that teachers ask, categorizing them at various levels of Bloom's taxonomy. The taxonomy which consists of seven categories defines the types of questions which could be used in each of Bloom's categories of thinking. The categories (table 1) include; (i) memory; involves recall or recognition of factual or conceptual information (fact, definition, generalization, and skill, true or false questions), (ii) translation; involves translating ideas from one communication to another, (iii) interpretation category involves questions relating facts, generalizations, definitions, values, and skills, to discover or use a relationship between two or more ideas (iv) application; presenting problems that approximate the form and context in which they would be encountered in life, (v) analysis; involves detecting, classifying, discriminating, categorizing, deduction, (vi) synthesis; engaging in imaginative, original thinking, where diverse solutions are elicited, (vii) evaluation; the process of making judgment about the value of an idea, a solution, a method, using criteria developed by the individual himself.

Teacher questions following Sanders' taxonomy require students to engage in specific kinds of thinking from low level recall of knowledge to higher level-evaluation type questions. If the classroom teacher is able to structure the questions according to the levels stipulated in the taxonomy, then the taxonomy offers a framework with which the teacher can determine the kinds of intellectual activities might require of his/her students. However, in developing/structuring or formulating the questions needed for classroom discussions, the taxonomy provides little support. Teachers are clear with the kind of intentions they want to achieve as well as the desired actions from students, such as students being able to make connections, use factual knowledge and create new understanding among others (Amos, 2002; Eshach et al., 2014). However they fail to formulate such questions as required for achieving these intentions.

N. M. Sanders (1972) also acknowledged the fact that even when teachers are trained in a respective taxonomy, they find it hard to put the taxonomy into practice. This is simply due to the fact that the many category distinctions of questions are not needed as they fragmentize into pieces that what teachers have conceptualized as whole. For example, the teachers generally know that questions fall into mainly two categories; factual and those questions that demand for students' thinking, reflection and connection of different ideas. In this case the teachers' challenge is not to categorize questions but to develop them. However Sanders' framework and many others seem to provide no explicit criteria for when the question categories should be used, and consequently the framework might not serve well for teachers as a guide for developing the desired questions. As Furst (1981) concluded about Bloom et al. (1956)'s taxonomy being not a suitable tool for classifying oral questions and facilitating classroom discussion, Sanders' taxonomy of questions also seems to focus more at the outcomes of instruction rather than at the language moves a teacher might undertake.

\section{Blosser (1973)'s question categories}

Blosser (1973) devised what she called the 'Question Category System for Science (QCSS)', consisting of four types of question categories (table 1); closed, open, managerial and rhetorical questions. Blosser describes managerial questions as those used by teachers to keep the classroom operating, move activities and pupils toward the desired goals for a given period or lesson (e.g. Will you turn to page 15 please?), and rhetorical questions as used by teachers to reinforce a point or for emphasis and teachers do not really anticipate an oral student response (the green coloring matter in plants is called chlorophyll, right?). Closed questions are those for which there are a limited number of acceptable 
responses or 'right answers', and it is expected that students have already had contact with the information being requested (e.g. What is the chemical formula for water?). Open questions on the other hand are questions according to Blosser which anticipate a wide range of acceptable responses rather than one or two 'right answers' and draw on students' past experiences, cause students to give opinions, reasons for given opinions, to infer or identify implications, formulate hypotheses, or make judgments based on their own values and standards. Blosser's category system was devised as a framework for teachers to analyze their questioning strategies, to be able to reduce the percentage of recall questions and increase the percentage of questions that require students to think. Indeed, she goes ahead to suggest that teachers can determine the types of questions they are using frequently by analysing the number of acceptable responses possible and to assess whether the question encourages or requires students to go beyond past information in formulating a response.

Blosser provides clear explanations for the question categories, the terms used and she also gives examples in each question category. There is an overall appreciation of the clarity and simplicity of what Blosser puts across. However, when it comes to developing classroom questions (written or oral), classifying questions as open or closed may not provide the sufficient support to teachers to able to develop questions. The definitions or explanations attached to open and closed are subject to different teacher interpretations and thus do not provide sufficient guide towards identifying suitable questions. Like Blosser argued, starting questions with 'why, explain, compare or interpret' may not warrant the kind of actions the students engage in and neither indicate the teacher's encouragement of students.

In addition Edward and Furlong, cited in Cazden (2001, pp. 92-93) also noted that identifying what is open and closed might be difficult for researchers owing to the context in which they are used. They argued that many questions appear to be open in one context only to be closed in another, and that distinguishing between open and closed might have to wait until the teacher intention is clearly spelt out. This difficulty also applies to teachers when they attempt to identify questions using the two distinctions of open and closed, and especially if the two categories are only differentiated by the range of answers or responses (that is one correct pre-defined answer for closed questions, and two or more for the open category). Blosser's question classification category therefore becomes of less use when it comes to developing or formulating questions for chemistry classrooms owing the lack of specificity in the used terms. The taxonomy however finds more productive application in the general classification of the questions that occur in classrooms.

\section{Nystrand and Gamoran (1997) and Minor (1966)'s categorizations}

Teacher questions were classified by Nystrand and Gamoran (1997) into two groups; that is authentic and test questions. Authentic questions were defined as those questions asked to get information, questions for which the asker (questioner) has not prespecified an answer. These kinds of questions include requests for information as well as open-ended questions, and indicate the priority the teacher places on thinking. On the other hand test questions were classified as questions for which only one possible right answer is allowed, questions of recitation, which allow students no control over the flow of the discussion. Nystrand and Gamoran (1997)'s classification is related to Minor (1966)'s conceptualization of teacher questions. Minor (1966) used the terms; 'real' and 'synthetic'. Real questions according to Minor, are those questions for which the questioners are yet to find answers, questions which make discovery possible and synthetic questions as questions having known answers (one possible known answer), which at best test a student's store of facts.

Considering the descriptions of the terms 'authentic' and or 'real' questions, it might well happen that the teacher comes into a situation where s/he does not know the answer, but such situations are rare or else usually occur when students are asking the questions. The purpose of the teacher asking questions is either to check for students' knowledge or to initiate a thinking operation and probably other functions as outlined in educational research. In all cases the teacher knows about the issue at hand and in addition s/he exhibits certain expectations regarding answers and all the time the teacher is obliged to exhibit a substantive amount of information to be able to execute the process. Thus the necessity of a teacher having full knowledge of what is being taught cannot be overlooked. Secondly, a teacher either knowing or not knowing answers to questions being asked seem not the 
most important part of a question but rather the value of the question in terms of objective achievement. A true/real question resides in its power to achieve a set objective rather than focusing on whether the teacher knows the answer or not.

There are other questioning situations where asking questions to which the questioner knows no answers is more pronounced. However classroom teaching questioning situations are treated uniquely owing to the unique functions attached to the nature and type of questions used. In everyday practice for example, it is common to ask questions where the questioner does not know the answer or when the questioner seeks information s/he does not have. This may not be the case with classroom teaching situations. In teaching, intentions are somehow different depending on the subject and the type of knowledge. Science teaching is about interpreting the world (phenomena) in a scientific way which often is different from the everyday interpretation. Therefore it is hard to imagine that questions to which the questioner knows no answer will service a similar purpose as it is now for the common questions in the education setting without changing the aims of an education program. Indeed like Cazden (2001) said, the criticisms of teachers asking questions for which they know the answers are over simplified and miss out on these important points. Eliciting students' thinking or making them to reflect on different concepts to construct new understanding, or having a dialogue with students in class is not dependent on asking questions for which the teacher knows no answers but on the ability to formulate questions in a form that will open up for the exploration of these aspects. In this respect Nystrand and Gamoran (1997) and Minor (1966)'s question conceptualizations, might not serve as suitable frameworks that could guide chemistry teachers in developing classroom questions.

\section{Fraenkel (1966)'s taxonomy of questions}

Fraenkel (1966) presented important arguments pertaining how to ask the 'right' questions, and even went ahead to suggest a taxonomy of questions that could help teachers in asking the "right" questions. He argued that there are several different types of questions which teachers may ask depending upon what purposes teachers have in mind. In this respect, these are the 'right' questions according to Fraenkel, questions which assist the teacher in achieving a particular objective or a set of objectives considered important in that particular context. He added that, teachers need to ask themselves and also attempt to find a satisfactory answer to the question; 'why they are doing what they do', that way, Fraenkel contends that teachers will be able to determine what questions to ask their students. He suggested a taxonomy of questions where questions are categorized in terms of the purposes which teachers might have, the actions required or desired of students, and the types of questions which teachers would ask accordingly (table 1).

The idea of first considering teachers' purposes, intentions, justifying reasons and students expected or desired actions/behavior as put forward by Fraenkel is key to getting started with formulating and using good questions. Given that classroom teachers understand the important role of questions as key elements in the learning process (Amos, 2002; Eshach et al., 2014), the close connection between the functions of questions and teacher intentions for asking would provide a basis for formulating the appropriate question types. Fraenkel's conceptualization of what right questions are appears to focus on the situational adequacy of the questions rather than their structural formation. The question's situational adequacy lies in the ability of that question to serve the purpose for which it is intended to serve (Roth, 1996). With this perspective, all questions will be good questions if they are able to serve the different purposes for which they are intended. Therefore the onus remains on the teacher to be able to clearly define his/her purpose/objectives or intentions and then try to formulate those questions that can help him or her to achieve the set out purposes/objectives.

Fraenkel's taxonomy is also perceived to be localized to the teaching settings. The taxonomy seems to align with the teachers' initial preparation stages prior to the lesson. It is common practice (formally or informally) that teachers often have a minute or more where they sit and contemplate on what they are going to teach in the next few minutes, the lesson purpose, lesson instructional approach and expected outcomes. That way, the taxonomy can be assimilated into the teacher's lesson plan without demanding much preparation and time from teachers. Teachers only need to stress out and reflect on their intentions, expected outcomes, students' behavior expected or desired students' outcomes and 
then try to formulate the kind of questions that could help them achieve their set targets. This way, the taxonomy could be of use to teachers as a guide to developing the questions used orally during classroom teaching and those for discussions even before going to the classrooms.

\section{Discussion}

In the analysis of the five question taxonomies explanations have been given to justify either the unsuitability or suitability of the individual taxonomies to serve as guiding frameworks for teachers for developing or formulating classroom questions. From the analysis, Fraenkel (1966)'s conceptualization of the 'right' questions seems to provide an appropriate way to conceptualize teacher questions. Fraenkel's taxonomy of questions appears to be more feasible as a framework that can be localized to teachers' thinking and perceptions, and it could serve with modifications as a framework for developing and using questions in classrooms. However, it must be stressed that the five question category systems (table 1) were exclusively examined in the context of being used by classroom teachers in developing or formulating questions and not the other purposes for which they are believed or perceived to serve. That way Fraenkel's framework was seen from the analysis as one which approximates serving this kind of purpose. This is due to the taxonomy's ability to account for teachers' role as developers of questions, allowing for teachers' participation as opposed to teachers being imposed on terms which are inconsistent with their own thinking.

One probable reason most question taxonomies have failed to help teachers improve their practice of questioning is due to those taxonomies failing to start from a level of knowledge, and thinking also shared by classroom teachers. Accounting for teachers' knowledge and thinking about the use of questions not only facilitate the uptake of suggested innovations by teachers, but can also facilitate teachers' transformation to the desired level of change, since teachers are put in a position where they able to value the innovation being introduced by relating to their own understanding, beliefs and attitudes.

\section{A framework to guide chemistry teachers in formulating good questions}

In order for Fraenkel (1966)'s taxonomy (as seen in table 1) to be used in chemistry classrooms, there is need to redefine the categories to suit the target curriculum or subject. For example, there is need to redefine the purpose, kind of questions desired in chemistry classrooms and the students' desired actions or outcomes. Fraenkel's categories are not communicating enough to be used by teachers to develop the kind of desired questions. For instance, in column 1 (see table 1) where he lists the purposes (knowledge acquisition, knowledge synthesis, analysis and creative thought), those kinds of purposes may be clear to education researchers and not to classroom teachers. It is difficult to understand what knowledge acquisition means in terms of a set purpose as it seems to carry a general understanding as the overall objective of a typical lesson. This can be replaced by letting the teacher state what purpose or objective he/she intends to achieve with students (for example, elicit thinking, check on masterly of concepts, use of facts to construct knew knowledge). The same applies to other categories in other columns where there is a general lack of specificity and direction for the terms being used.

In figure 1, I propose a framework to guide chemistry teachers in developing or formulating classroom questions. The proposed framework is based on Fraenkel (1966)'s conceptualization of the 'right questions', whereby questions are considered right or good based on the extent to which they assist the teacher to achieve a particular objective or set of objectives. The framework comprises of two non-hierarchical levels and a knowledge base. At level 1 the teacher determines and sets the intentions or the purpose for the questioning situation, which might be connected to the objectives of the lesson. The teacher also starts to think about the kind of expectations from the students or the nature of actions he/she wants to elicit or the desired students' outcomes. After thinking and working through both the purpose and students' desired actions, at level 2, the teacher then starts to formulate the types of questions which tally with both his/her intentions and the desired students' outcomes. The knowledge base provides examples of the possible types of questions and some hints on how to restructure or formulate the desired questions. 
The three types of questions recall, algorithmic, and conceptual which are possible in chemistry classrooms, which are given in the proposed framework are described by Nurrenbern and Robinson (1998). Recall type questions also known as factual questions ask students to recall facts, equations, or explanations. Algorithmic type questions ask students to use information or processes in a familiar way similar to the operation of programmed computers, and follow a prescribed algorithm or procedure. Conceptual questions are questions used to tap students' understanding of chemical ideas. These questions challenge students to articulate their understanding and students have the opportunity to elaborate on their ideas and construct conceptual knowledge.

In the proposed framework, questions are evaluated as effective based on their situational adequacy and the extent to which they are able to achieve teacher set objectives/intentions or desired outcomes. The teacher needs to match his/her intentions with the kind of behavior or students' actions desired or expected. He/she has to think about the kind of questions that can help him/her in achieving what he/she has set out to achieve in the particular lesson. Here the teacher looks at the possible range of questions from recall, algorithmic, and conceptual questions, and then s/he determines which kinds of questions are suitable for a given purpose. The framework is not restrictive in its form and allows the teacher to think about what he/she intends to do and the kind of questions that could be used to achieve what he/she has set out.

\section{Practical aspects in regard to effective questioning and the use of the framework}

There are important aspects that I bring to the attention of teachers in regard to being able to formulate and use appropriate and good classroom questions. First, the proposed framework only serves as a guide to formulating the desired questions depending on the teaching purpose as determined by the teacher. Reading or studying the framework may not warrant being able to formulate good questions. Like R. E. Sanders (1993) argued, good questioning develops with practice and teachers need to continuously put into practice the knowledge and strategies proposed in the framework in order to develop the skill of formulating good questions.

Second, it has been suggested by researchers in the past that to able to ask useful questions, teachers need to have a good knowledge of subject matter (Carlsen, 1987; Chin, 2007; Harris, Phillips, \& Penuel, 2012). They need to have a masterly of science ideas and some anticipatory sense about how to move students forward in their thinking (Harris et al., 2012), as well as the pedagogical skills in crafting and sequencing the appropriate questions that progressively build on previous ones Chin (2007). In addition to these requirements, teachers need some form of orientation in the possible kinds of questions and how to structure or formulate these questions. The proposed framework will be productive only if teachers have the opportunity to work through it and continuously try to formulate or restructure questions that match their desired students' outcomes or set purposes.

Third, teacher questions and particularly oral questions do not occur in isolation of other classroom activities during the teaching situation. Questions serve a myriad of functions, both cognitive social functions and being able to improve one's questioning requires understanding these functions (Farrar, 1986). The type of questions and the nature of questioning are also closely linked with the method of instruction the teacher uses and thus for a teacher who wants to use questions effectively will need to rethink his/her instruction approach. The proposed framework provides question formulation hints and question examples for the nature of questions that can occur in inquiry classrooms. However, to be able to work with such questions where the interest is in giving a chanceto students to participate in knowledge construction, the teacher will need to adopt an instruction/teaching approach that provides for these opportunities. 
Figure 1: A framework for developing questions for chemistry classrooms

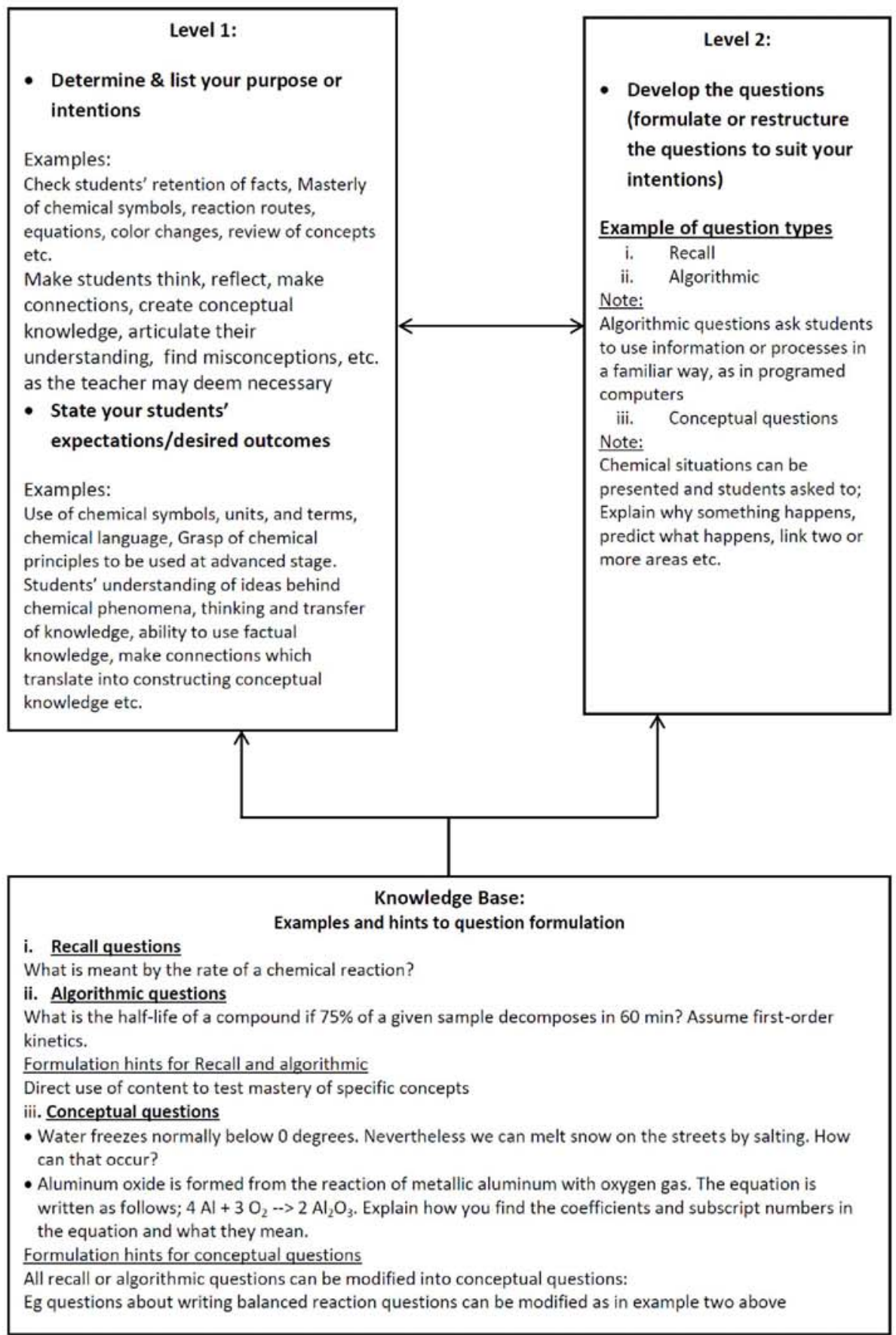

Forth, there have been concerns about the complexity of question classification taxonomies which make them difficult for teachers to use in their teaching (Anderson, 1994). The issue complexity surfaces mainly if the concepts or strategies proposed in the taxonomies are alien to teachers and are inconsistent with their thinking about classroom questioning practice. It might happen that teachers 
will start to think, plan and make use of question classification taxonomies if trained regardless of the complexity, as also supported from Marzano and Kendall (2007)'s submission that "the more familiar one is with a process, the more quickly one executes it and the easier it becomes". However, like N. M. Sanders (1972) argued the teachers are likely to abandon the use of such taxonomies along the way owing to their incompatibility with the teaching contexts. The proposed framework is perceived to provide support to ensure that the teacher takes a step to think about and work on formulating those questions that he/she thinks will support students' understanding. The teacher is pivotal and a key determinant as regards the proposed scheme. It differs from other frameworks in way that it does not impose external terms to the teacher but rather the teacher has the mantle to formulate his questions to his end, depending on the situational need and adequacy.

\section{Summary}

In this paper, five question category systems (question classification taxonomies) by different authors have been examined with respect to the extent to which they could guide chemistry teachers in formulating good classroom questions. A framework has been suggested to guide chemistry teachers in formulating and using classroom questions. There is no need for a conceptual refinement of the categories used or theory grounding for that matter. The reason is that the basis for the framework lies majorly on the teacher setting out intentions and then goes ahead to work out those questions that can facilitate the achievement of the set intentions/purposes. Finally, though the implementation of the outlined steps in using the proposed framework seems trivial and simple, teachers need to be oriented in the scheme and how it can be incoporated into their daily planning. As the next step, it is hoped that this framework will be empirically tested for its reliability, validity and usefulness.

\section{References}

Adams, T. H. (1964). The development of a method for analysis of questions asked by teachers in classroom discussion. (Doctoral dissertation), Rutgers State University, Ann Arbor, MI: University Microfilms.

Alison, K. (1994). Guiding knowledge construction in the classroom: Effects of teaching children how to question and how to explain. American Educational Research Journal, 31(2), 338-368. doi:10.2307/1163313

Allen, D., \& Tanner, K. (2002). Approaches to cell biology teaching: Questions about questions. Cell Biology Education, 1(3), 6367. Retrieved from http://dx.doi.org/10.1187/cbe.02-07-0021

Amos, S. (2002). Teachers' questions in the science classroom. In S. Amos \& R. Boohan (Eds.), Aspects of teaching secondary science: perspectives on practice. London: Routledge.

Anderson, L. W. (1994). Research on teaching and teacher education. In L. W. Anderson \& L. A. Sosniak (Eds.), Bloom's taxonomy: A forty year retrospective (pp. 139-141). Chicago, IL: University of Chicago Press.

Anderson, L. W., Krathwohl, D. R., Airasian, P. W., Cruikshank, K. A., Mayer, R. E., Pintrich, P. R., . . Wittrock, M. C. (2001). A taxonomy for learning, teaching, and assessing: A revision of Bloom's taxonomy of educational objectives. White Plains, NY: Longman.

Aschner, M. J. (1961). Asking questions to trigger thinking. NEA Journal, 50(6), 44-46.

Barnes, D. (1969). Language in the secondary classroom In D. R. Barnes, J. N. Britton, \& M. Torbe (Eds.), Language, the learner and the school (pp. 11-77). Harmondsworth: Penguin.

Biber, D., Johansson, S., Leech, G., Conrad, S., \& Finegan, E. (1999). Longman grammar of spoken and written english Harlow, UK: Pearson Education ESL

Bloom, B. S., Engelhart, M. D., Furst, E. J., Hill, W. H., \& Krathwohl, D. R. (1956). Taxonomy of educational objectives: The classification of education goals. Cognitive domain. New York, NY: David McKay.

Blosser, P. E. (1973). Handbook of effective questioning techniques. Worthington, OH: Education Associates

Carlsen, W. S. (1987). Why do you ask? The effects of science teacher subject-matter knowledge on teacher questioning and classroom discourse.

Carner, R. L. (1963). Levels of questioning. Education, 83(9), 546-550. Retrieved from <Go to ISI>://WOS:A1963CCA1300006

Cazden, C. B. (2001). Classroom discourse: The language of teaching and learning (2 ed.). Portsmouth, NH: Heinemann.

Chin, C. (2007). Teacher questioning in science classrooms: Approaches that stimulate productive thinking. Journal of Research in Science Teaching, 44(6), 815-843.

Chinn, C. A., Anderson, R. C., \& Waggoner, M. A. (2001). Patterns of discourse in two kinds of literature discussion. Reading Research Quarterly, 36(4), 378-411. doi:10.2307/748057

Christenbury, L., \& Kelly, P. P. (1983). Questioning: A path to critical thinking. Retrieved from Washington, DC:

Clegg, A. A. (1987). Why questions. In W. W. Wilen (Ed.), Questions, questioning techniques, and effective teaching (pp. 11-22). Washington D C: National Education Association. 
Clements, M. H., Fielder, W. R., \& Tabachnick, R. B. (1966). Social study: Inquiry in elementary classrooms. New York, NY: BobbsMerrill Company.

Clements, R. D. (1964). Art student-teacher questioning. Studies in Art Education, 6(1), 14-19. doi:10.2307/1319655

Crump, C. (1970). Teachers, questions, and cognition. Educational Leadership, 27(7), 657-660.

Davis, J., \& Tinsley, D. C. (1967). Cognitive objectives revealed by classroom questions asked by social studies student teachers. Peabody Journal of Education, 45(1), 21-26. doi:10.2307/1491443

Douglass, M. P. (1967). Social studies: From theory to practice in elementary education. New York, NY: J.B. Lippincott Co.

Elstgeest, J. (1985). The right question at the right time. In J. Elstgeest \& W. Harlen (Eds.), Taking the plunge : How to teach primary science more effectively for ages 5 to 12. Portsmouth, NH: Heinemann

Enokson, R. (1973). A simplified teacher question classification model. Education, 94(1), 27-29.

Eshach, H., Dor-Ziderman, Y., \& Yefroimsky, Y. (2014). Question asking in the science classroom: Teacher attitudes and practices. Journal of Science Education and Technology, 23(1), 67-81.

Farrar, M. T. (1986). Teacher questions: The complexity of the cognitively simple. Instructional Science, 15(2), 89-107. doi:10.2307/23368989

Fraenkel, J. R. (1966). Ask the right questions! The Clearing House, 41(4), 199-202. doi:10.2307/30180565

Furst, E. J. (1981). Bloom's taxonomy of educational objectives for the cognitive domain: Philosophical and educational issues. Review of Educational Research, 51(4), 441-453.

Galassi, J. P., Gall, M. D., Dunning, B., \& Banks, H. (1974). The use of written versus videotape instruction to train teachers in questioning skills. The Journal of Experimental Educational, 16-23.

Gall, M. D. (1970). The use of questions in teaching. Review of Educational Research, 40(5), 707-721. Retrieved from http://www.jstor.org/stable/pdfplus/1169463.pdf

Gallagher, J. J., \& Aschner, M. J. (1963). A preliminary report on analyses of classroom interaction. Merrill-Palmer Quarterly of Behavior and Development, 9(3), 183-194. doi:10.2307/23082786

Galton, M. J., Simon, B., \& Croll, P. (1980). Inside the primary classroom. London: Routledge and Kegan Paul.

Gilbert, S. W. (1992). Systematic questioning: Taxonomies that develop critical thinking skills. Science Teacher, 59(9), 41-46.

Godbold, J. V. (1973). Teacher training for effective questioning. Retrieved from Washington, DC:

Graesser, A. C., Person, N., \& Huber, J. (1992). Mechanisms that generate questions. In T. W. Lauer, E. Peacock, \& A. C. Graesser (Eds.), Questions and information systems (pp. 167-187). Hillsdale NJ: Lawrence Erlbaum Associates.

Graesser, A. C., \& Person, N. K. (1994). Question asking during tutoring. American Educational Research Journal, 31(1), 104-137.

Guilford, J. P. (1956). The structure of intellect. Psychological Bulletin, 53(4), 267-293. doi:10.1037/h0040755

Guszak, F. J. (1967). Teacher questioning and reading. The Reading Teacher, 21(3), 227-234. doi:10.2307/20195903

Hamblen, K. A. (1984). The application of questioning strategy research to art criticism instruction. Paper presented at the annual meeting of the American Educational Research Association, New Orleans, LA.

Hannel, I. (2009). Insufficient questioning. The Phi Delta Kappan, 91(3), 65-69. doi:10.2307/40345093

Harris, C. J., Phillips, R. S., \& Penuel, W. R. (2012). Examining teachers' instructional moves aimed at developing students' ideas and questions in learner-centered science classrooms. Journal of Science Teacher Education, 23(7), 769-788. Retrieved from http://dx.doi.org/10.1007/s10972-011-9237-0

Herber, H. L. (1978). Teaching reading in content areas. Englewood Cliffs, NJ: Prentice-Hall.

Hunkins, F. P. (1972). Questioning strategies and techniques. Boston, MA: Allyn \& Bacon, Inc.

Hyman, R. T. (1979). Strategic questioning. Englewood Cliffs, NJ: Prentice-Hall

Kaiser, A. (1979). Questioning techniques: A practical guide to better communication. Pomona, CA: Hunter House.

Kastberg, S. E. (2003). Using Bloom's taxonomy as a framework for classroom assessment. The Mathematics Teacher, 96(6), $402-$ 405. doi:10.2307/20871367

Lee, Y., \& Kinzie, M. B. (2012). Teacher question and student response with regard to cognition and language use. Instructional Science: An International Journal of the Learning Sciences, 40(6), 857-874. Retrieved from http://www.eric.ed.gov/ERICWebPortal/detail?accno=EJ983164

Long, M. H., \& Sato, C. (1983). Classroom foreigner talk discourse: Forms and functions of teachers' questions. In H. W. Seliger \& M. H. Long (Eds.), Classroom oriented research in second language acquisition (pp. 268-286). Cambridge: Newbury House Publishers, Inc.

Marzano, R. J. (2001). Designing a new taxonomy of educational objectives. Thousand Oaks, CA: Corwin Press.

Marzano, R. J., \& Kendall, J. S. (2007). The new taxonomy of educational objectives. Thousand Oaks, CA: Corwin Press.

Minor, F. (1966). In resonance with students. Educational Leadership, 23(7), 537-540.

Mortimer, E., \& Scott, P. (2003). Meaning making in secondary science classrooms. Maidenhead: Open University Press.

Moyer, J. R. (1965). An exploratory study of questioning in the instructional processes in selected elementary schools. (Doctoral dissertation), Teachers College, Columbia University, Ann Arbor, MI.

Nurrenbern, S. C., \& Robinson, W. R. (1998). Conceptual questions and challenge problems. Journal of Chemical Education, 75(11), 1502. doi:10.1021/ed075p1502

Nystrand, M., \& Gamoran, A. (1997). The big picture: Language and learning in hundreds of english lessons. In M. Nystrand, A. Gamoran, R. Kachur, \& C. Prendergast (Eds.), Opening dialogue: Understanding the dynamics of language and learning in the english classroom (pp. 30-74). New York, NY: Teachers College Press.

Parsons, T. W. (1968). Guided self-analysis system for professional development program III-teaching for inquiry (Schedule A questioning strategies). Retrieved from Berkeley, CA:

Pate, R. T., \& Bremer, N. H. (1967). Guiding learning through skilful questioning. The Elementary School Journal, 67(8), 417-422. doi:10.2307/1001009 
Reed, R. L. (1977). Questioning and its implications for educational research. Détroit, MI: Michigan State University.

Riegle, R. P. (1976). Classifying classroom questions. Journal of Teacher Education, 27(2), 156.

Roth, W. M. (1996). Teacher questioning in an open-inquiry learning environment: Interactions of context, content, and student responses. Journal of Research in Science Teaching, 33(7), 709-736. doi:10.1002/(SICI)1098-2736(199609)33:7<709::AIDTEA2>3.0.CO;2-R

Ruddell, R. B. (1974). Reading-language instruction: Innovative practices. Englewood Cliffs, NJ: Prentice-Hall, Inc.

Sanders, N. M. (1966). Classroom questions: What kinds? New York, NY: Harper \& Row

Sanders, N. M. (1972). A Second look at classroom questions. The High School Journal, 55(6), 265-277. doi:10.2307/40365787

Sanders, R. E. (1993). The art of effective trainer questioning. ISA Transactions, 32(1), 19-21. doi:http://dx.doi.org/10.1016/00190578(93)90007-J

Schreiber, J. E. (1967). Teachers' question-asking techniques in social studies. Unpublished Doctoral Dissertation. University of Iowa. Smith, B. O., Meux, M. O., \& Coombs, J. (1960). A Study of the logic of teaching (0252001303). Retrieved from Urbana, IL:

Smith, R. J. (1969). Questions for teachers: Creative reading. The Reading Teacher, 22(5), 430-439. doi:10.2307/20196146

Taba, H. (1967). Implementing thinking as an objective in social studies. In J. Fair \& F. R. Shaftel (Eds.), Effective thinking in the social studies: 37 th Yearbook (pp. 25-49). Washington, DC: National Council for the Social Studies.

Vogler, K. E. (2005). Improve your verbal questioning. The Clearing House, 79(2), 98-103. doi:10.2307/30182119

Wilen, W. W. (1985). Questioning, thinking and effective citizenship. Social Science Record, 22(1), 4-6.

Wilen, W. W. (1986). Questioning skills, for teachers. Washington, D.C.: National Education Association.

Wilen, W. W. (1991). Questioning skills, for teachers. What research says to the teacher. Washington, DC: National Education Association.

Wimer, J. W., Ridenour, C. S., Thomas, K., \& Place, A. W. (2001). Higher order teacher questioning of boys and girls in elementary mathematics classrooms. The Journal of Educational Research, 95(2), 84-92. Retrieved from http://www.jstor.org/stable/27542363 